\title{
PHASE-CONTRAST MICROSCOPY OF THE ANIMAL VITREOUS BODY*
}

\author{
BY
}

\author{
B. A. BEMBRIDGE, G. N. C. CRAWFORD, AND ANTOINETTE PIRIE
}

From the Nuffield Laboratory of Ophthalmology and the

Department of Human Anatomy, Oxford

A STUDY of the structure of the vitreous body has been made by means of phase-contrast microscopy. Shortly after work began, Schwarz and Schuchardt (1950) described the structure of the vitreous of various animals using this method as well as dark-ground illumination. However, it was thought worth while to continue our study as we were specially interested in trying to determine the chemical nature of the fibres and membranes seen, and their distribution within the vitreous body. The chemistry of the vitreous was not investigated by Schwarz and Schuchardt (1950). Later, however, following its examination with the electron microscope, Schwarz (1951) and Matoltsy and others (1951) concluded that one type of fibre from the vitreous body is probably a primitive collagen. This confirms the chemical analyses of the residual protein by Pirie, Schmidt, and Waters (1948).

The work described in this paper has been mainly concerned with the vitreous body of the ox. No wide investigation of other animals has been attempted, but it seemed worth while examining the vitreous body of birds as there is evidence that its embryological origin is different from that of mammals (Mann, 1949). We also examined the vitreous of the monkey, since that of man is almost impossible to obtain fresh and in the normal state.

\section{Methods}

In order to determine its structure, pieces of fresh vitreous were removed and examined, without further treatment, by phase-contrast microscopy. The various structures seen were then treated with enzymes in order to get information on their chemical composition.

Material.-The eyes were brought from the slaughterhouse within one hour of the death of the animal and were either stored in the refrigerator or used at once. In all cases, unless the contrary is stated, the description of the microscopic structure is based on the examination of absolutely fresh specimens. The method of opening the eye to get a piece of vitreous for examination depended on the site of the specimen needed, and is best described later under the separate headings. In all cases a small piece of the fresh vitreous in situ in the eye was grasped with forceps and cut off with scissors. It was then placed on a slide with a drop of

\footnotetext{
- Received for publication November 10, 1951.
} 
saline, sometimes being teased to make as thin a preparation as possible, and a coverslip was put on. The preparation was immediately examined with a Beck positive phase-contrast microscope. The eyes of the pigeons and monkeys were removed immediately after the creatures were killed and were examined in the same way.

For photography a $90^{\circ}$ positive phase-contrast microscope* was used, the objective in all cases being the $4 \mathrm{~mm}$. N.A. 0.65 .

Enzyme preparations used for treatment of the vitreous were :

Crystalline trypsin $\dagger$ made up $10 \mathrm{mg} . / \mathrm{ml}$. in phosphate saline $p \mathrm{H} \mathrm{7}$;

Collagenase $\neq$ from Clostridium welchii made up $2-4 \mathrm{mg} . / \mathrm{ml}$. in borate or saline $p \mathrm{H} 7$;

Hyaluronidase extracted from acetone-dried rabbit testis with dilute acetic acid and used after neutralization and centrifugation.

\section{Results}

Ox Vitreous Body. - We found three different structures within the vitreous body :

(1) coarse branching fibres attaching the vitreous body at its base;

(2) very fine parallel fibres running through the main body of the vitreous;

(3) a hyaline membrane surrounding the vitreous.

These structures would all be included in the preparations of residual protein made from whole vitreous body by filtration and washing. It seems therefore that "residual protein" is a mixture of substances and not a chemical entity.

Coarse Branching Fibres of the Ciliary Region.-To demonstrate these the sclera alone is incised half-way round the equator. A piece of sclera is then removed extending from the equator to near the limbus, thus forming a band-shaped window revealing the choroid. The latter is removed and then the retina, leaving the vitreous surface exposed. At the front edge of the window the tooth-like ciliary processes can be seen. If the cut edge of sclera near the limbus is gently pulled with forceps, parallel lines of strain can often be seen extending from the ciliary processes over the surface of the vitreous and into its substance, in much the same way as traction on the lens shows the lines of tension of the zonular fibres. A piece of vitreous body nipped off from this region contains coarse branching fibres whose thickness is about $0.5-3.0 \mu$. Typical preparations are shown in Figs 1 and 2. When such preparations are viewed by phase-contrast it is necessary to decide whether the structures seen are true fibres or merely creases in a membrane. In support of the former interpretation is the fact that the mode of branching which is quite frequently seen would be unlikely to occur in a crumpled membrane. Moreover, the free ends of the criss-crossing fibres can often be found (Fig. 1).

Many observers have noticed that the vitreous body is firmly attached to the ciliary processses; if it is pulled away from the sclera and choroid in this region a ring of pigmented processes tears off and remains adherent to the vitreous body.

* Made by Cooke, Troughton, and Simms. The photographs were taken by a Leica camera and Leica eyepiece camera attachment, the film being Kodak Microfile Panchromatic.

+ Armour and Co., London.

$\ddagger$ Prepared by Dr. R. O. Thomson, Wellcome Research Laboratories. 


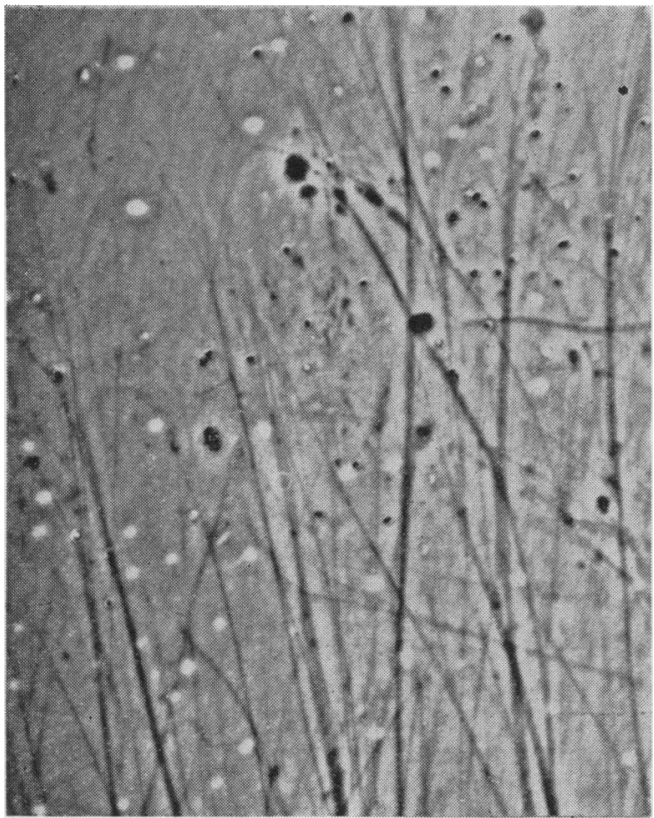

Fig. 1.-Ox, free ends of coarse fibres from ciliary region.

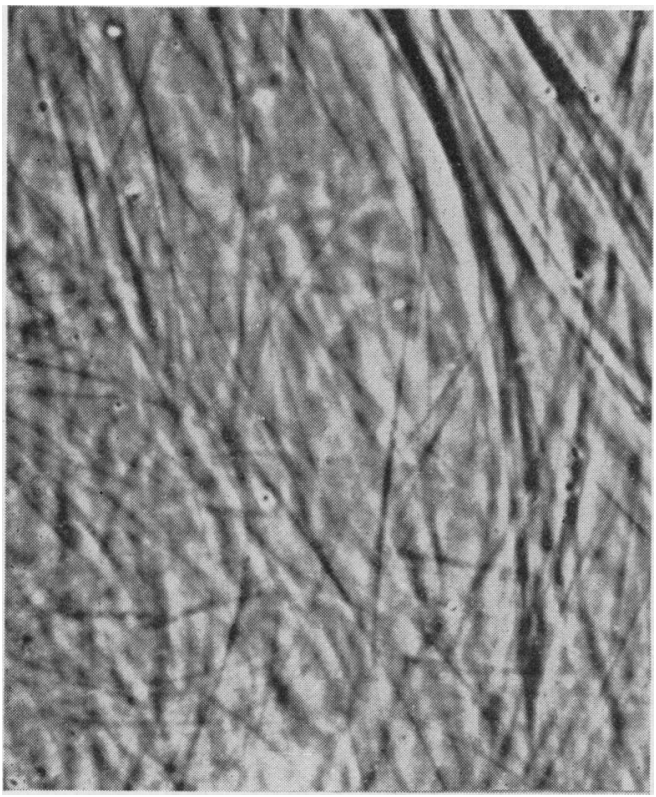

Fig. 2.- Ox, coarse branching fibres from ciliary region.

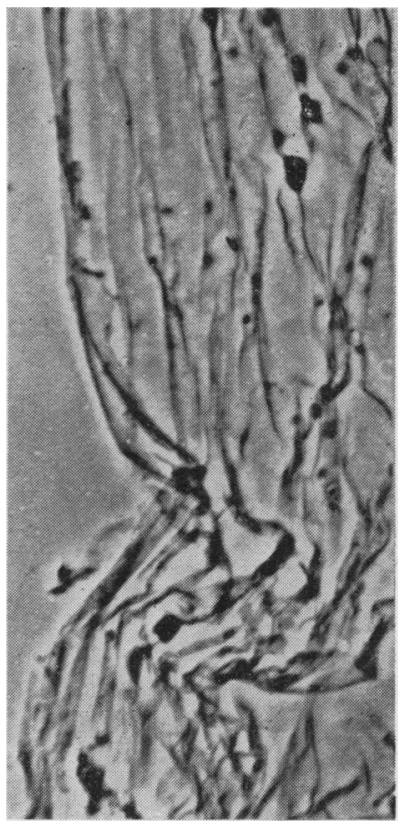

Fig. 3.-Ox, hyaline membrane of surface of vitreous body.

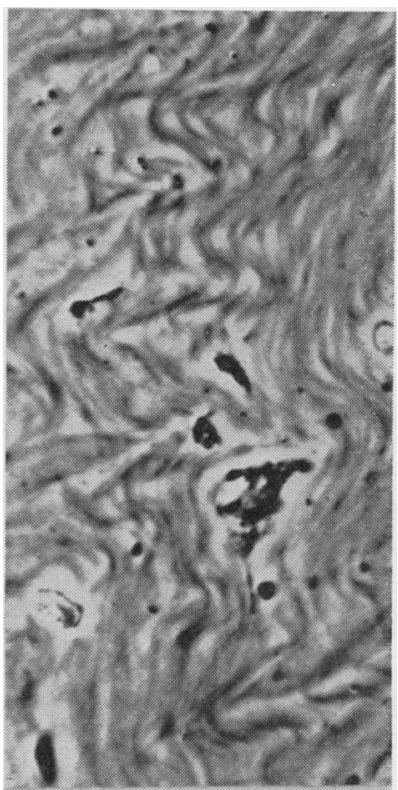

Fig. 4.-Ox, fine fibres lying in waves.

Phase-contrast photographs of the unfixed and unstained vitreous body. Approx. $\times 700$. 
It is possibly from these processes that the coarse fibres have their origin. The fibres are evidently a true part of vitreous structure. They not only run on the surface of the vitreous but also extend into its substance. Coarse branching fibres cannot be found in vitreous preparations from behind the equator or from the centre of the vitreous body.

Preparations of fresh vitreous such as those employed here do not reveal the direction in which the fibres run in the intact vitreous body. Schwarz and Schuchardt (1950) described fibres $1.3-2.9 \mu$ wide as extending towards the centre of the vitreous, but since their preparations were made in the same way as our own it is difficult to see on what evidence this conclusion is based.

Fine Parallel Fibres.-If a small piece of fresh vitreous is removed through a scleral opening at or behind the equator and examined microscopically no coarse branching fibres are seen. Instead, there are strands of very fine parallel fibres which are sometimes straight (Fig. 5) and sometimes in waves (Fig. 4). These are particularly obvious if some of the fluid in the small piece of vitreous jelly is allowed to drip away before the preparation is put on the slide. We have stressed that microscopic preparations show the fibres to be parallel. In fact, the fibres are so fine that their fibrous nature can only be detected by the appearance of this parallel striation. Slight pressure of coverslip might make fibres connected in a network take a parallel course, as do the strings in a network string bag when the bag as a whole is stretched in one direction. Therefore, though we speak of the fibres as "parallel" fine fibres, it is not assumed that they exist in this arrangement within the vitreous.

Preparations showing these fibres can readily be made from the peripheral part of the vitreous, particularly near the equator. They are more difficult to see in preparations from the posterior surface or from the central core of the vitreous body. However, preparations made by cutting out small pieces of vitreous from these regions and allowing them to drain to about one third their original size contain typical fine fibres. They appear to be more concentrated at the periphery than in the vitreous core.

Friedenwald and Stiehler (1935) showed that, if cattle vitreous bodies are cut into outer and inner fragments, an insoluble material is contained in and can be recovered from all parts. The vitreous is thus not simply a homogeneous jelly encased in a membranous bag; it has an internal structure as well. This has been confirmed by cutting a frozen eye so that the vitreous was separated into front, back, side, and centre pieces. The fragments were weighed and then washed by suspension in distilled water for several days to remove salts and other soluble constituents. They were then dried and re-weighed, and the weight of insoluble residue $/ 100 \mathrm{~g}$. fresh vitreous calculated. The back and the side pieces were combined as it would have been impossible to weigh each separately. The weight of residue from each area was : vitreous front, $21.3 \mathrm{mg} . / 100 \mathrm{~g}$. ; vitreous back and sides, $17.3 \mathrm{mg} . / 100 \mathrm{~g}$.; vitreous centre, $12.7 \mathrm{mg} . / 100 \mathrm{~g}$. These figures show that the centre of the vitreous contains about half as much insoluble material as the periphery.

Hyaline Membrane.-In many preparations made from the surface of the vitreous body small pieces of an optically homogeneous hyaline membrane can be found, looking very like a piece of crumpled cellophane (Fig. 3). Preparations of this membrane can be made more readily from eyes which have remained 
overnight in the refrigerator than from absolutely fresh eyes. This suggests that in the fresh eye the membrane is more firmly attached to the retina and is thus difficult to detach from it. However, since preparations of membrane have been made from completely fresh eyes, particularly by dissection under saline, there is little doubt that the membrane is present in vivo and is not an artefact. When the point of a knife is gently pushed through the surface of a fresh cattle vitreous and then withdrawn, the vitreous herniates through the puncture. This seems to show that the surface is bounded by a membrane of some kind. As the hyaline membrane can be prepared from entirely fresh vitreous it seems logical to consider that herniation occurs owing to puncture of a membrane.

Effect of Collagenase and Trypsin on Vitreous Structures.-Pirie and others (1948) have shown that collagenase preparations from $\mathrm{Cl}$. welchii liquefy the ox vitreous body, but that trypsin does not do so. The effect of preparations of these two enzymes on the microscopic structure of the ox vitreous body has therefore been examined.

Addition of either enzyme to preparations mounted on microscope slides gave unsatisfactory results. The enzymes were slow to act, perhaps owing to their slow rate of penetration into the vitreous gel, and the preparations dried during overnight incubation. Strips of vitreous body taken from the required position were therefore immersed in enzyme solutions with the addition of one drop of chloroform, and the mixture incubated in small stoppered bottles at $37^{\circ}$. Control strips were incubated in saline. Hyaluronidase, prepared from rabbit testis, was added to both control and test preparations to accelerate the rate of penetration by breakdown of the vitreous hyaluronic acid. Preparations were usually examined after incubation overnight. The gross appearance was noted and if there was a tangible residue it was examined microscopically. The enzymes affect the structures in different ways. Trypsin digests the coarse branching fibres and the hyaline membrane but not the fine fibres, wheras collagenase digests the fine fibres and the hyaline membrane, but not the coarse branching fibres. Both collagenase and trypsin preparations probably contain other enzymes and it could be argued that it is these unknown enzymes that are effective. There is no evidence for this and it seems more reasonable to assume that it is the main enzyme of the preparation that digests the fibres.

TABLE I

EFFECT OF ENZYMES ON VITREOUS STRUCTURE OF OXEN

\begin{tabular}{c|c|c|c}
\hline Type of Structure & Coarse Branching Fibres & Membrane & Fine Fibres \\
\hline Trypsin & digested & digested & not changed \\
digested & not changed & digested \\
\hline
\end{tabular}


These results, together with the fact that collagenase liquefies the vitreous (Pirie and others, 1948), suggest that the fine parallel fibres are the main structural element in the vitreous mass. In the earlier work great care was taken to free the vitreous body from the pigmented processes at its base and it is probable that most of that region of vitreous containing the coarse branching fibres was removed with the pigmented processes. If the entire vitreous body, including the ring of pigmented processes, is injected with collagenase and digestion is allowed to proceed to completion, the mass of vitreous is liquefied but there remains a thin ring of pigmented processes. This residue seen under phase-contrast shows only the coarse branching fibres. It therefore seems likely that these fibres originate in the ciliary region and pass only a short way into the vitreous mass.

If a complete vitreous body is treated with trypsin the mass remains intact, but the pigmented ring at the base is dissolved and the fluid surrounding the vitreous becomes full of pigment granules. This confirms the smaller scale experiments which showed that trypsin digests the coarse branching fibres.

Pigeon Vitreous Body.-The dissection and examination of the pigeon vitreous body was made in the manner previously described. The structures found differed from those of oxen in two ways. No coarse branching fibres could be seen and the material making up the mass of the vitreous showed a granular appearance and it was difficult to decide whether true fibres were present. Figs 6 and 7 show preparations from the equatorial region of the pigeon vitreous. Preparations showing the hyaline membrane could easily be made and Fig. 8 shows the typical appearance. Pigeon vitreous body is firmly attached to the ciliary processes and microscopic preparations made from this region, which show no coarse branching fibres, contain sheets of the hyaline membrane. Attachment of the vitreous body may be made through this. Enzyme digestion of pigeon vitreous body showed that it is almost completely digested by collagenase. The residue consists of fragments of the ring of pigmented ciliary processes held together by sheets of cells. Trypsin did not liquefy the vitreous mass but digested the hyaline membrane. Preparations were examined, after digestion, both with the naked eye and microscopically.

Monkey Vitreous BoDY.-The monkey eye showed an interesting difference from those of the ox and pigeon in that it was extremely difficult to separate the vitreous body from the retina. This was so whether or not the eye was dissected under saline. If a " window" was made in the sclera and the choroid was then removed leaving the retina in position it was almost impossible to brush or scrape off the retina without injury to the vitreous. In the other animals examined the retina can be peeled off the vitreous quite easily even immediately after death. The vitreous was less viscous than that of cattle and pigeon and a cut through its surface usually caused semi-fluid jelly to escape. 


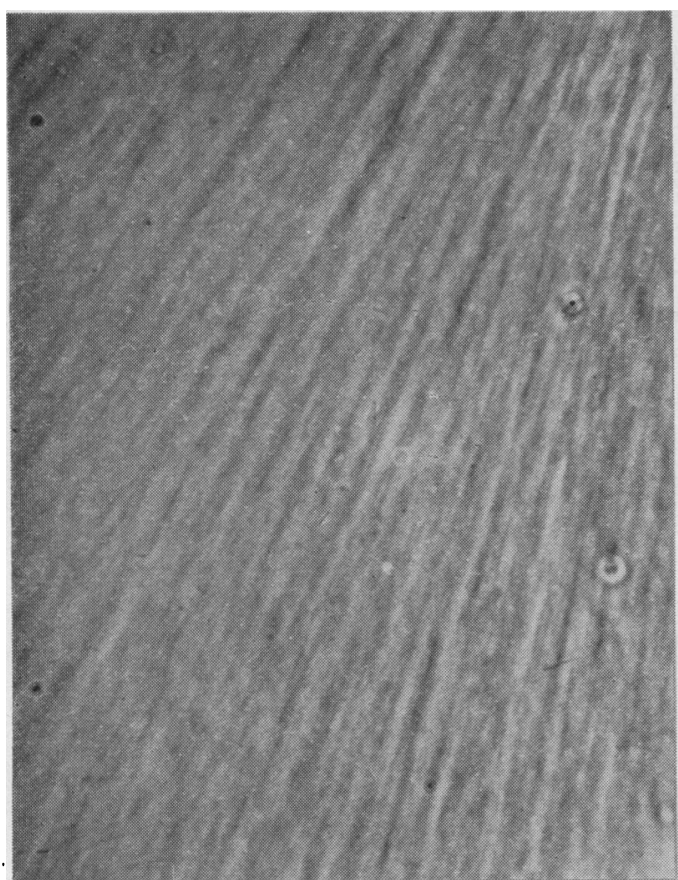

Fig. 5.-Ox, parallel strands of fine fibres of vitreous mass.

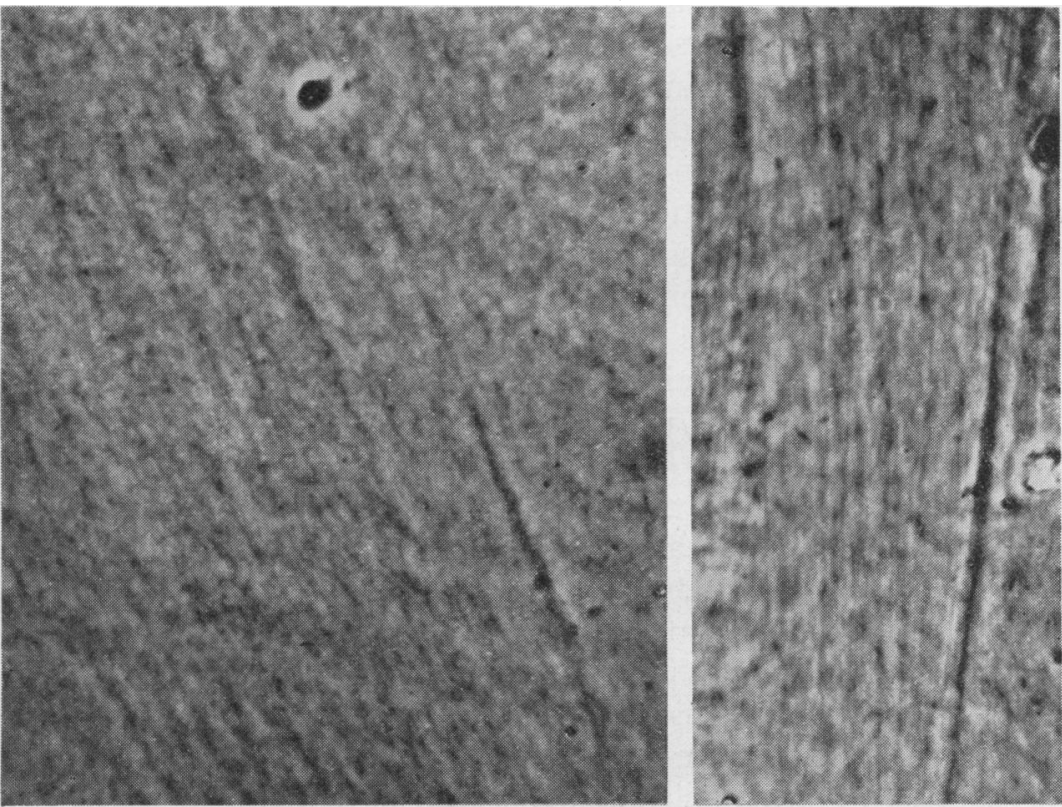

FIGs 6 and 7.-Pigeon, granular material of vitreous mass. 
Preparations of monkey vitreous from the ciliary region showed coarse fibres attached to the ciliary processes, very similar to those of cattle (Figs 9 and 10). Preparations made from the other parts of the vitreous body showed very fine parallel fibres. Fig. 11 shows two layers of these crisscrossing and Fig. 12 a more granular type of fibre reminiscent of those seen in the pigeon. In no preparation were we able to see a hyaline membrane. This may be because our method of dissection is unsuitable, the membrane being left attached to the retina. More drastic treatment might reveal it, but since only a limited number of eyes were available, it seemed better to repeat exactly the techniques used with other animals in order to make a direct comparison. A single experiment to find the effect of enzymes on monkey vitreous showed that the coarse fibres were digested by trypsin, but not by collagenase, and the fine fibres of the vitreous mass by collagenase but not by trypsin.

\section{Discussion}

The question arises whether the microscopic appearances reported in this study are artefacts. There is considerable evidence, derived from slit-lamp examination of the vitreous during life and from work with animal eyes, that the vitreous has an organized structure. The vitreous bodies used in our experiments have in most cases been examined within one hour of death and it seems improbable therefore that the appearance of the fibres is due to postmortem changes. Moreover, they remain stable over long periods. They are found in eyes as different as those of ox, pigeon, and monkey, and this also is in favour of the view that they are present in vivo, for artefacts might be expected to be more diverse. Collagen from rat tail tendon, but not most other sources, can be taken into solution in weak acid and reprecipitated as fibres at neutrality or by addition of salts (Nageotte, 1927). We do not think it can be argued that any such precipitation of soluble collagen as fibres takes place between enucleation of the eye and examination of the vitreous microscopically. The $p \mathrm{H}$ and salt concentration of the normal vitreous are such that any collagen present will be insoluble in vivo. Friedenwald and Stiehler (1935), studying the vitreous with the ultramicroscope, concluded that it consists of sheets laid down parallel to the surface. They were satisfied that the sheets were not optical artefacts.

Schwarz and Schuchardt (1950), using phase-contrast and dark-ground illumination, found fibres in the ciliary region that can be identified with the coarse branching fibres we have found. They also described a network of finer fibres in the body of the vitreous and immediately behind the lens. We have not seen any network structure except in vitreous which had previously been frozen at $-40^{\circ} \mathrm{F}$. The difference may be due to difference in method of examination since we have used a magnification of $\times 600$ whereas Schwarz and Schuchardt, judging from their photographs, used magnifications of $\times 70$ to $\times 100$. With this magnification it would be difficult to detect the fine parallel fibre pattern. 

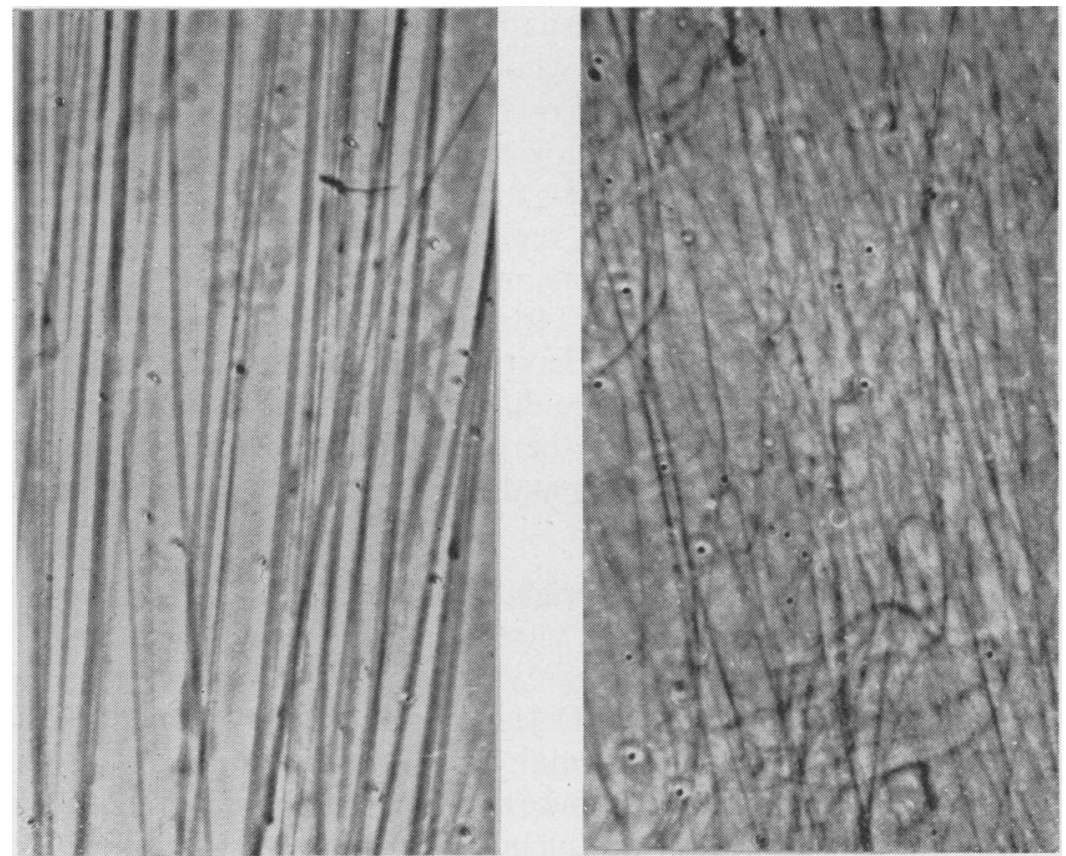

FIGS 9 and 10.-Monkey, coarse branching fibres from ciliary region.

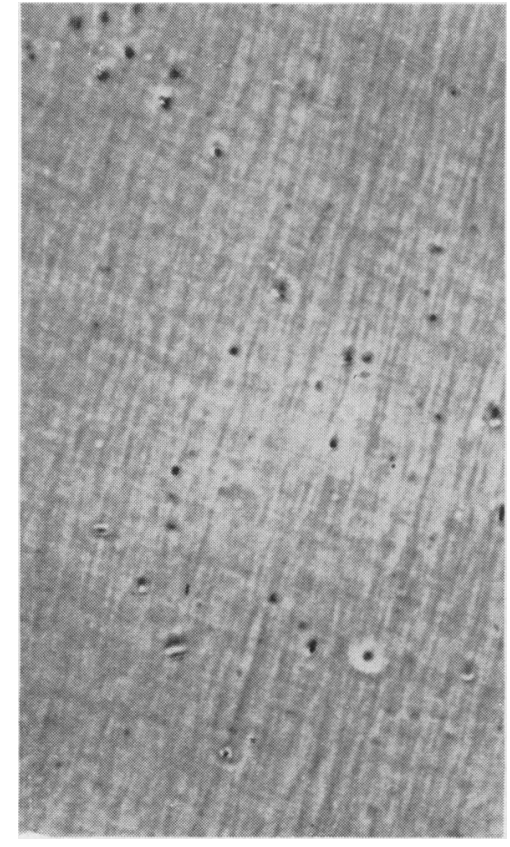

Fig. 11.-Monkey, fine fibres of vitreous mass; two levels criss-crossing.

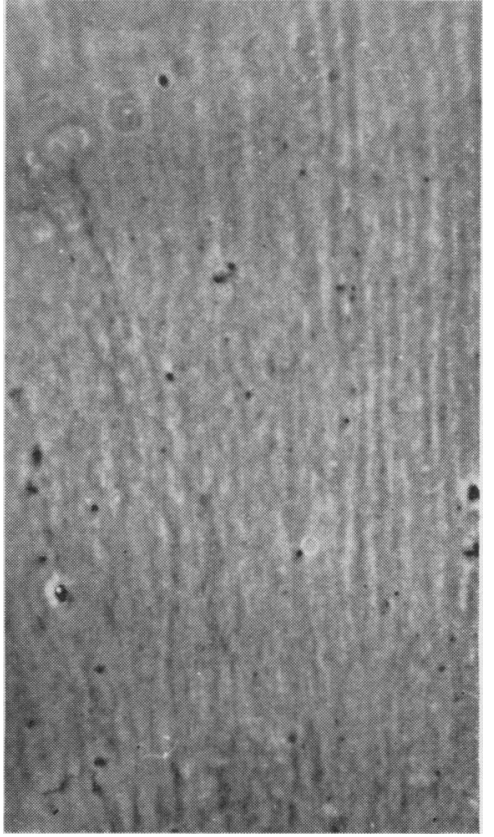

Fig. 12.-Monkey, granular type of fine fibres of vitreous mass. 
The adult vitreous body has usually been considered as uniform in structure, except by embryologists who have described its multiple origin. Examination by phase-contrast microscopy combined with enzyme analysis has shown that it is both morphologically and chemically complex. The insoluble protein of the main vitreous mass reacts like collagen to enzymes, but the vitreous body at the ciliary region contains another fibrous protein resistant to collagenase. The hyaline membrane again differs in its digestibility by enzymes and in its structure trom both types of fibre. These results are of some interest in any consideration of pathological changes in the vitreous, where one or other of these different constituents may be involved.

It remains to discuss the relation between the microscopical findings, the embryological origin of the vitreous and the appearances seen in the human vitreous on slit-lamp examination.

Correlation with Embryological Origin of Vitreous Body.-Which cell layers contribute to the structure of the vitreous body is still uncertain. Mann (1949) considers that the adult human vitreous is practically entirely derived from the neural ectoderm, whereas Dejean and Granel (1947) deduce that the vitreous structure is largely mesodermal, as it stains histologically in the same way as collagen. Reconciliation of these two views can be achieved if the neural ectoderm is thought capable of producing a protein somewhat like the typical mesodermal protein collagen, or if we accept the view of Polyak (1941) that sóme of the glial cells of the retina are mesodermal and that these form vitreous fibrils. The structure of the vitreous body, as indicated by phasecontrast microscopy and chemical analysis, may then be correlated with that described by embryologists (Table II).

TABLE II

\begin{tabular}{|c|c|c|c|}
\hline Type of Structure & Coarse Branching Fibres & Fine Parallel Fibres & Hyaline Membrane \\
\hline $\begin{array}{lll}\text { Position } & \ldots & \ldots\end{array}$ & ciliary region only & vitreous mass & vitreous surface \\
\hline Enzyme Digestion & $\begin{array}{l}\text { trypsin digests; collagen- } \\
\text { ase has no effect }\end{array}$ & $\begin{array}{l}\text { trypsin has no } \\
\text { effect; collagen- } \\
\text { ase liquefies }\end{array}$ & $\begin{array}{l}\text { digested by collagen } \\
\text { ase and trypsin }\end{array}$ \\
\hline $\begin{array}{l}\text { Suggested Cell } \\
\text { Origin } \quad \ldots\end{array}$ & neuroectoderm & $\begin{array}{l}\text { glial cells of retina } \\
\text { or neuroectoderm }\end{array}$ & - \\
\hline $\begin{array}{l}\text { Position in Mann's } \\
\text { Scheme of Vitre- } \\
\text { ous Development }\end{array}$ & tertiary vitreous fibres & $\begin{array}{l}\text { secondary vitreous } \\
\text { fibres formed } \\
\text { from inner layer } \\
\text { of optic cup by } \\
\text { outgrowth of sus- } \\
\text { tentacular fibres } \\
\text { of Müller }\end{array}$ & - \\
\hline
\end{tabular}


The supposition that neuroectoderm can produce a collagen protein gains support from a consideration of the vitreous of the bird which has very little mesoderm in its origin (Mann, 1949). Phase-contrast examination shows that the mass of the bird's vitreous is made up of material which is more granular than, but is reminiscent of, the fine parallel fibres of the mammalian vitreous and this material is liquefied by collagenase. It must therefore be concluded that some non-mesodermal cells have produced a protein that reacts to enzymes in the same way as the mesodermal protein collagen. Or we may designate some retinal glial cells as mesodermal (Polyak, 1941) and assign to these the formation of vitreous fibrils.

The evidence derived from phase-contrast microscopy and enzyme digestibility does not help to decide the origin of the hyaline membrane bounding the vitreous. Mann (1949) considers that the internal limiting membrane is formed from the foot plates of the fibres of Müller, but as this membrane stains differently from Müller's fibres, Wolff (1948) considers that this cannot be so. The fact that the hyaline membrane seems to be digested by both trypsin and collagenase suggests that it is different from the vitreous fibres and similar to the lens capsule which reacts to these enzymes in the same way (Pirie, 1951).

Correlation with Slit-Lamp Appearances.-Illustrations in the slit-lamp atlases of Vogt (1941) and Berliner (1949) show many different appearances in the pathological vitreous. The normal vitreous is less full of incident but observers agree that it is not optically empty. A wavy curtain-like structure is seen behind the lens, and filmy membranes deeper within the vitreous body have been described. Preparations of ox vitreous taken from immediately behind the lens show nothing except the fine fibres of the main vitreous mass. It is possible that in the human eye the curtain-like appearance is given by the anterior vitreous boundary whether there is an extra membrane present or not.

The filmy membranes seen in the deeper parts of the vitreous body may be related to the fine fibres seen in phase-contrast preparations.

The pathological vitreous may show three main differences from the normal :

(1) there may be knotted-up shreds of fibres and membranes;

(2) there may be shrinkage of vitreous to give a boundary line within the eye between the shrunken vitreous lying in the bottom of the eye and an optically empty space above;

(3) there may be the appearance of vitreous detachment with a hole in the membrane on the back face.

The first two appearances can be accounted for in terms of the microscopical appearances seen with phase-contrast; the third needs more attention. It is possible that the same appearance could be given by detachment of the vitreous, leaving the internal limiting membrane attached to the retina, or by detachment of vitreous together with the internal limiting membrane. A decision on this point would be very interesting as it seems 
to have a bearing on the relation between vitreous detachment and detachment of the retina.

The results given in this paper are preliminary only. In particular, the spatial relation between the three structures described-coarse branching fibres, fine fibres, and hyaline membrane-needs further study. The front limit of the hyaline membrane has not been defined in any eye and the

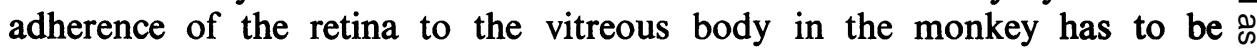
examined. The earlier results of Schwarz and Schuchardt (1950) demon- $\overrightarrow{0}$ strated the value of phase-contrast microscopy in the examination of the eye. The present study shows that such microscopy, combined with enzyme $\stackrel{\omega}{\sigma}$ analysis, can help to characterize the various structures of the vitreous body. $\frac{\circ}{\circ}$

\section{Summary}

(1) Examination of the fresh vitreous body of ox, pigeon, and monkey by phase-contrast microscopy shows that the vitreous of these animals has a complex structure of fibres and membrane.

(2) The effect of the enzymes collagenase and trypsin on these structures is described and it is concluded that they are chemically different.

(3) The relationship of the microscopic appearances to the embryological origin and slit-lamp appearances of the vitreous is discussed.

We have pleasure in acknowledging gifts of collagenase preparations from Dr. R. O. Thomson of the Wellcome Research Laboratories, and also wish to thank the staff of the Oxford and District Co-operative Slaughterhouse for their help.in obtaining fresh ox eyes.

\section{REFERENCES}

Berliner, M. L. (1949). "Biomicroscopy of the Eye", vol. 2. Hoeber, New York. Dejean, C., and Granel, F. (1947). Tabul. Amst. Biol., 22 (Oculus-Pars 1) 158.

Friedenwald, J. S., and Stiehler, R. D. (1935). Arch. Ophthal., Chicago., 14, 789.

Matoltsy, A. G., Gross, J., and Grignolo, A. (1951). Proc. Soc. exp. Biol., N.Y., 76, 857.

MANN, I. (1949)." "The Development of the Human Eye", 2nd ed. Brit. Med. Ass., London.

Nageotte, J. (1927). C. R. Soc. Biol., Paris, 96, 172.

PIRIE, A. (1951). Biochem. J., 48, 368.

PCHMIDT, G., and WATERS. J. W., (1948). British Journal of Ophthalmology, 32, 321.

PolyaK, S. L. (1941). " "The Retina". University Press, Chicago.

SCHWARZ, W. (1951). Z Z. Zellforsch., 36, 45.

and SchuchardT, E. (1950). Ibid., 35, 293.

VoGT, A. (1941). "Handbook and Atlas of the Slit-Lamp Microscopy of the Living Eye", vol. 3, Eng. trans. 2nd ed. Schweizer Druck- und Verlagshaus, Zürich.

WolfF, E. (1948). "The Anatomy of the Eye and Orbit", 3rd ed. Lewis, London. 